\title{
Evaluation of Precancerous Breast Lesion Upgrade Rate
}

\author{
Esmat Alsadat Hashemi ${ }^{1}$, Shahpar Haghighat ${ }^{2}$, Asieh Olfatbakhsh ${ }^{1}$, Maryam \\ Jafari $^{1}$, Mehrdad Yasaei $^{3}$
}

${ }^{1}$ Breast Diseases Department, Breast Cancer Research Center, Motamed Cancer Institute, ACECR, Tehran, Iran. ${ }^{2}$ Quality of Life Department, Breast Cancer Research Center, Motamed Cancer Institute, ACECR, Tehran, Iran. ${ }^{3}$ Shahid Beheshti University, Tehran, Iran.

\begin{abstract}
Background: Breast imaging guided core-needle biopsy enable the assessment of suspected precancerous lesions. In some precancerous lesion there is a risk of upgrading to cancer after surgical removal. This study was conducted to determine the upgrading rate of CNB-diagnosed precancerous breast lesions. Methods: A retrospective study was conducted to examine the data of patients who had undergone core needle biopsy from April 2016 to March 2019 at the Radiology Department of the Breast Clinic of Motamed Cancer Institute and whose pathological reports were indicative of a precancerous lesion such as atypical ductal hyperplasia, sclerosing adenosis, flat epithelial atypia or papillary lesion and had undergone surgery for this lesion. The upgrading rate and its related factors such as the size of the lesion, patient's age, family history of breast cancer and method of core-needle biopsy were analyzed in SPSS software. Results: A total of 241 patients were recruited with a pathological report of pre-cancerous predisposing lesions. The mean age of the patients was 42.14 years and the highest upgrading rates in the analysis were observed for papillary lesion (19.3\%) and atypical ductal hyperplasia, $(21.4 \%)$, while the upgrading rates were $(1.2 \%)$ for sclerosing adenosis and $(0 \%)$ for flat epithelial atypia. Data analysis showed that the lesions' upgrading rate correlated with the lesion's size $(\mathrm{P}=0.005)$. Conclusion: The findings of this study showed that size of the lesions increase the risk of upgrading to cancer, which is much higher in papillary lesion and atypical ductal hyperplasia compared to sclerosing adenosis and flat epithelial atypia. It seems that surgical excision of the entire lesion in patients with larger mass size may decrease the upgrading rate of cancer. Conducting specific studies on each distinct lesion can help yield more conclusive results.
\end{abstract}

Keywords: Breast cancer- precancerous lesions- core-needle biopsy- Iran

Asian Pac J Cancer Care, 6 (4), 461-466

\section{Introduction}

About $10 \%$ of patients who undergo screening mammography for breast cancer show an indication for additional imaging techniques. In approximately $8-10 \%$ of these cases, the findings may lead to breast biopsy. These findings can be reported as the presence of a mass, microcalcification, architectural distortion or focal asymmetry, which are construed as indications for additional imaging. The radiologist may report the existing lesion as suspicious and recommend a biopsy based on the results of these additional imaging techniques. In the case of non-palpable breast lesions, the standard method is Core Needle Biopsy (CNB) guided by either of the imaging techniques including mammography, ultrasound and MRI.
Submission Date: 09/30/2020 Acceptance Date: 08/17/2021

\footnotetext{
Corresponding Author:

Dr. Esmat Alsadat Hashemi

Breast Diseases Department, Breast Cancer Research Center, Motamed Cancer Institute, ACECR, Tehran, Iran.

Email: hashemy1277@yahoo.com
}

CNB can be either conventional or vacuum-assisted and be guided by ultrasound or mammography (stereotactic).

$\mathrm{CNB}$ is the standard method for the diagnosis of suspected lesions in the breast and is less costly compared to surgery and yields results that are consistent with the pathological report obtained by surgical biopsy in $95 \%$ of the cases [1-3].

The pathology report of CNB can determine whether there is a need for surgery in the patient. An important point is the conformity of the pathology and radiology findings. If a radiologist reports a lesion suspected of cancer but the pathologic findings indicate a benign lesion, surgery will be necessary for definitive diagnosis. In some 
cases, the pathology report may suggest a pre-cancerous lesion such as Atypical Ductal Hyperplasia (ADH), Sclerosing Adenosis (SA), Flat Epithelial Atypia (FEA) or Papillary Lesion (PL), which have indications for surgery in order to reduce the risk of future cancer and to get a more precise diagnosis. Post-surgical pathology reports may be similar to the initial pathological report or may be worse and indicate invasive cancer.

Sclerosing Adenosis (SA) is one of the benign lesions that may be identified in CNB pathology reports; despite its high prevalence, this lesion is not well-known. In pathological terms, this proliferative lesion is associated with an increase in convoluted lobules and stromal fibrosis. Several studies have investigated the association of SA with breast cancer and have revealed different results [4].

Also, in some cases, the pathology report following surgery may reveal a more severe condition compared to $\mathrm{CNB}$. ADH is one of these proliferative lesions that develop in the mammary epithelial tissue. The presence of this lesion in the breast increases the risk of invasive cancer in the breast four- or five-fold. Various studies have reported a $7-87 \%$ discrepancy between CNB pathology and surgical pathology with respect to the presence of non-invasive or invasive cancer in ADH [5-11]. In other words, the upgrading rate of the lesions in different studies is highly variable. At the same time, due to the high risk of breast cancer development in these lesions, it is reasonable to recommend surgical removal to prevent this risk when $\mathrm{ADH}$ is confirmed by CNB [12-13].

Papillary lesion (PL) is a benign lesion with a lower prevalence in the breast that is seen in the ultrasound as a single lesion or multiple lesions. In some cases, the patient does not have any specific clinical symptoms, while in some patients, blood or serous fluid secreted from the nipple raises suspicion, which can then be confirmed by an ultrasound. In these cases, too, the patient can undergo CNB. Previous studies have reported the upgrading rate of these lesions after surgery as $11 \%$ [14].

Flat epithelial atypia (FEA) is a new diagnostic term that is expressed in pathologic reports following CNB and is usually associated with other benign or malignant breast lesions. Due to this association, when this lesion is present in the pathology report following CNB, the site of the lesion is recommended to be removed with surgery, particularly if detected in the mammography despite microcalcification and if, after sampling, calcium deposits are still detected in the control mammogram [15-16]. According to studies, four cases of breast cancer are reported in the post-surgical pathology in every 1,000 patients [17-19].

The present study was designed in view of the differences of opinion about upgrading rates after surgery and the need for more extensive interventions. The results can guide the surgeon's decision for surgical procedures and the rate of tissue removal and, at the same time, help present preventive therapies for patients who are prone to breast cancer.

\section{Materials and Methods}

This cohort study was conducted on candidates of CNB guided by one of the imaging techniques due to a suspicious lesion observed in the ultrasound or mammogram who had then undergone surgery within a maximum of one month at the Breast Clinic of Motamed Cancer Institute, Culture and Research. Data on the imaging reports, post-CNB pathology and post-surgical pathology were collected and compared. Upgrading rate in different studies had been reported between $7-87$ percent [5-11]. So upgrading rate, $\alpha$ error and absolute precision of current study were considered equal to $0.47,0.05$ and 0.07 , respectively and 198 samples was the sample size were estimated 198 patients.

Breast Clinic of Motamed Cancer Institute is a multidisciplinary center in Tehran. Referred patients are examined by surgeons and different diagnostic and treatment modalities are achieved according to its updated guideline [12].

Of the 2582 patients who had undergone CNB guided by one of the imaging techniques from April 2017 to March 2020 at the Radiology Department of the Breast Clinic of Motamed Cancer Institute, 241 whose pathologic reports indicated one of the listed pre-cancerous lesions and had their lesion surgically removed by a surgeon and whose medical files were complete were recruited.

\section{Definition of upgrading}

A change in any of the pre-cancerous lesions diagnosed as Atypical Ductal Hyperplasia (ADH), Sclerosing Adenosis (SA), Flat Epithelial Atypia (FEA) or Papillary Lesion (PL) to in-situ or invasive carcinoma in the post-surgical pathology is considered an instance of upgrade. Since the transformation of any of the noted pre-cancerous lesions to ADH is considered an upgrade and deems breast cancer preventive measures necessary, the upgrade of FEA, SA and PL detected in the surgery as $\mathrm{ADH}$ was also considered a general instance of upgrade. This study was conducted to examine the relationship between demographic and clinical variables, including the patient's age, family history of breast cancer, size of the mass, biopsy method, pathology according to CNB, pathology according to the surgery and the upgrading rate of the lesion. The study was accepted in scientific committee of Breast Cancer Research Center and received the ethics committee approval (code No. IR.ACECR. IBCRC. REC.1394.47).

\section{Statistical analysis}

The absolute and relative frequency of demographic and clinical characteristics and upgrading rates were reported by descriptive statistical tests. The relationship of upgrading rate with other variables was analyzed by Pearson Chi-Square and Fisher's Exact Tests. 


\section{Results}

The mean age of the patients was $42.14( \pm 9.8)$ years. Table 1 presents the frequency of each of the variables. The most frequent pre-cancerous lesion in the CNB (49.4\%) was PL, 23 (19.3\%) of which were diagnosed as cancer in the surgical pathology.

According to the findings of Table 2, the upgrading rate of the lesions was also different of lesions. The highest

Table 1. The Absolute and Relative Frequency of the Demographic and Clinical Variables in the Subjects $(\mathrm{n}=241)$

\begin{tabular}{|c|c|c|}
\hline Variable & Number & Percentage \\
\hline \multicolumn{3}{|l|}{ Age (year) } \\
\hline$<30$ & 29 & 12 \\
\hline $30-50$ & 180 & 74.7 \\
\hline$>50$ & 32 & 13.3 \\
\hline \multicolumn{3}{|c|}{ Family history of breast cancer } \\
\hline Positive & 43 & 17.8 \\
\hline Negative & 198 & 82.2 \\
\hline \multicolumn{3}{|l|}{ Size of the lesion $(\mathrm{cm})$} \\
\hline$=<2$ & 226 & 93.8 \\
\hline$>2-5$ & 15 & 6.2 \\
\hline \multicolumn{3}{|l|}{ Biopsy method } \\
\hline $\mathrm{CNB}^{* * *}$ & 208 & 86.3 \\
\hline Vacuum-assisted CNB & 25 & 10.4 \\
\hline Stereotactic CNB & 8 & 3.3 \\
\hline \multicolumn{3}{|l|}{ Biopsy pathology } \\
\hline $\mathrm{ADH}$ & 28 & 11.6 \\
\hline SA & 83 & 34.4 \\
\hline FEA & 11 & 4.6 \\
\hline PL & 119 & 49.4 \\
\hline \multicolumn{3}{|l|}{ Surgical pathology** } \\
\hline $\mathrm{ADH}$ & 17 & 7.1 \\
\hline SA & 67 & 27.8 \\
\hline FEA & 7 & 2.9 \\
\hline PL & 84 & 34.9 \\
\hline Carcinoma & 19 & 7.9 \\
\hline Other benign lesions * & 47 & 19.5 \\
\hline
\end{tabular}

upgrading rate were noticed in $\mathrm{ADH}(21.4 \%)$ and $\mathrm{PL}$ $(19.3 \%)$ and the lowest rates $(1 \%$ and $0 \%)$ in SA and FEA, respectively $(\mathrm{p}$-value $=0.033)$.

The second part of the data analysis examined the relationship of each study variable with the upgrading rate using Pearson Chi-Square and Fisher's Exact Test (Table 3). The findings of this table show that the upgrading rate was higher in patients with a lesion larger than $2 \mathrm{~cm}$ compared to those with a lesion smaller than or equal to $2 \mathrm{~cm}$. The results of this analysis showed a significant relationship between size of the lesion and upgrading rate at the significance level of $5 \%(\mathrm{P}=0.005)$.

Also, according to the findings of the study, the upgrading rate was higher in patients over age 50 compared to patients younger than $50(\mathrm{P}=0.088)$.

As for family history of breast cancer, as shown in Table 3, the upgrading rate was higher in patients with a positive family history compared to those with a negative family history; however, this correlation was not significant $(\mathrm{P}=0.546)$.

As for $\mathrm{CNB}$ method, the upgrading rate was higher in the conventional $\mathrm{CNB}$ method compared to vacuum-assisted and stereotactic $\mathrm{CNB}$; however, this correlation was not significant at the significance level of $0.05(\mathrm{P}=0.55)$.

\section{Discussion}

Benign breast conditions include a wide range of histopathologic lesions. Of the many benign types of these lesions, only a small number are clinically considered pre-cancerous or predisposing lesions of breast cancer.

A history of benign lesion biopsy in a patient's breast, especially if the result of the pathology has shown a proliferative lesion, suggests an increased risk of breast cancer in the future.

The present study was conducted to determine the upgrading rate of pre-cancerous lesions and the factors affecting it and examined 241 women who had undergone CNB guided by mammography or ultrasound followed by a surgery at the Radiology Clinic of the Breast Clinic of the Academic Center for Education, Culture, and Research.

The results show that the upgrading rate was the highest for $\mathrm{Pl}(19.3 \%)$ and $\mathrm{ADH}(21.4 \%)$ and the lowest ( $1 \%$ ) for SA and $(0 \%)$ for FEA, which is somewhat similar to the results obtained by Chae and Mooney, who reported the upgrading rate for $\mathrm{ADH}$ as $22.2 \%$ and $18 \%$, respectively $[13,20]$. According to a study by Dyrstad

Table 2. The Upgrading Rate in Each of the Pre-cancerous Lesions

\begin{tabular}{lccccc}
\hline Upgrading & \multicolumn{3}{c}{ Biopsy Pathology* } \\
& ADH & SA & FEA & PL & Total \\
\hline Negative & 22 & 82 & 11 & 96 & 211 \\
& $78.60 \%$ & $98.80 \%$ & $100 \%$ & $80.70 \%$ & $87.60 \%$ \\
Positive & 6 & 1 & 0 & 23 & 30 \\
Total & $21.40 \%$ & $1.20 \%$ & $11.30 \%$ & 119 & $12.40 \%$ \\
& 28 & 83 & $100 \%$ & $100 \%$ & 241 \\
\hline
\end{tabular}

*Atypical Ductal Hyperplasia (ADH), Sclerosing Adenosis (SA), Flat Epithelial Atypia (FEA), Papillary Lesion (PL) 
Table 3. The Relationship between Upgrading and Demographic and Clinical Variables

\begin{tabular}{lccc}
\hline Variable & \multicolumn{2}{c}{ Upgrading Frequency (Percentage) } & P-Value \\
& Yes & No & $0.088^{* *}$ \\
\hline Age (year) & $21(10.8)$ & & \\
$\quad<50$ & $9(19.6)$ & $37(80.4)$ & $0.546^{* *}$ \\
$\quad \geq 50$ & & & \\
Family history of breast cancer & $5(11.6)$ & $38(88.4)$ & $<0.005^{* *}$ \\
$\quad$ Positive & $25(12.6)$ & $173(87.4)$ & $0.550^{*}$ \\
$\quad$ Negative & $24(10.6)$ & $202(89.4)$ & $9(60)$ \\
Size of the lesion (cm) & $6(40)$ & $181(87)$ & $30(88)$ \\
$\quad=<2$ & $27(13.0)$ & & \\
$>2-5$ & $3(12.0)$ & & \\
Biopsy method & & & \\
CNB & & & \\
Vacuum-Assisted/Stereotactic & & & \\
\hline
\end{tabular}

*Pearson Chi-Square Test, **Fisher's Exact Test

suggesting a 3.93 -fold increase in the risk of breast cancer in proliferative lesions, preventive therapeutic measures can only be recommended to these patients if the upgrading rate obtained in this study for ADH and PL are taken into consideration [21]. Obviously, the presence of other risk factors of breast cancer in the patient, such as a high density of mammary tissue in the mammography, necessitates the use of additional diagnostic methods and ultimately surgery for the removal of the suspicious lesion in order to reduce the risk of cancer [22-24]. Particularly in cases where there is a discrepancy between the results of imaging and $\mathrm{CNB}$, the physician should candidate the patient for the surgical removal of the lesion [25].

In cases where CNB indicates a papillary lesion in the breast, the probability of CNB errors in detecting papillary cancer in these lesions should be taken into account as well [26-27]. In papillary lesions, especially if combined with atypia, or if conventional CNB has been administered, it is advisable to remove the lesion by surgery. Some studies have shown evidence of cancerous lesions along with these lesions and advised to remove these lesions with proper margins [28-31].

In the present study, the upgrading rate for papillary lesions was $19.3 \%$, which is less than that reported in previous studies ( 0 to $29 \%$ ), which might be due to the smaller sample size from each of the pre-cancerous lesions in this study [32]. The biopsy method also affects the upgrading rate. This study found a lower upgrading rate in the patients undergone vacuum-assisted CNB compared to those undergone conventional CNB (12\% vs. $13 \%)$, which could be related to the volume of extracted tissue as per the explanations. Seely et al. suggested that, in cases where the lesion is small and not associated with atypia and when vacuum-assisted biopsy is used, the surgery decision may be disclaimed and the patient might be put under periodical monitoring [33].

In the case of SA and FEA, the upgrading rate was $1.2 \% \& 0 \%$ in this study, which, given the wide range of upgrading rates obtained for these lesions in different studies $(0-35 \%)$, means a difference of opinion about whether to remove these lesions or put the patient under regular monitoring observe. The different upgrading rates of these lesions in the present study might be due to the small sample size in each of the pre-cancerous lesions compared to the other studies, which have examined only one type of lesion. In some cases, however, these lesions are associated with other pre-cancerous lesions that may not be detected in conventional CNB. In these instances, the patient's age, positive family history of breast cancer or size of the lesion may be important factors in the surgeon's choice of treatment. Since vacuum-assisted CNB yielded more precise results, it helps offer the patient better recommendations.

In conclusion, Overall, the results of this study showed that, in patients with large lesions and a pathology report of ADH or PL, the probability of upgrading is higher and the patient must undergo surgery to remove the lesion. In the case of SA or FEA, a proper decision needs to be made according to each patient's particular circumstances for reducing the risk of future cancer. Unnecessary surgeries may be preventable by periodic follow-ups in some lowrisk cases. However, we acknowledge that the number of cases in our study for each pre-cancerous lesion was not large enough. Further studies with larger sample sizes are necessary for obtaining more accurate results.

\section{Acknowledgmens}

None declared.

\section{References}

1. Dahlstrom J, Sutton S, Jain S. Histological precision of stereotactic core biopsy in diagnosis of malignant and premalignant breast lesions. Histopathology. 1996 06;28(6):537-541. https://doi.org/10.1046/j.1365-2559.1996.d01-463.x

2. Jackman RJ, Nowels KW, Shepard MJ, Finkelstein SI, Marzoni FA. Stereotaxic large-core needle biopsy of 450 nonpalpable breast lesions with surgical correlation in lesions with cancer 
or atypical hyperplasia. Radiology. 1994 Oct;193(1):91-95. https://doi.org/10.1148/radiology.193.1.8090927

3. Parker SH, Lovin JD, Jobe WE, Burke BJ, Hopper KD, Yakes WF. Nonpalpable breast lesions: stereotactic automated large-core biopsies.. Radiology. 1991 08;180(2):403-407. https://doi.org/10.1148/radiology.180.2.1648757

4. Visscher DW, Nassar A, Degnim AC, Frost MH, Vierkant RA, Frank RD, Tarabishy Y, Radisky DC, Hartmann LC. Sclerosing adenosis and risk of breast cancer. Breast Cancer Research and Treatment. 2014 02;144(1):205-212. https:// doi.org/10.1007/s10549-014-2862-5

5. Liberman L, Cohen MA, Dershaw DD, Abramson AF, Hann LE, Rosen PP. Atypical ductal hyperplasia diagnosed at stereotaxic core biopsy of breast lesions: an indication for surgical biopsy.. American Journal of Roentgenology. 1995 05;164(5):1111-1113. https://doi.org/10.2214/ ajr.164.5.7717215

6. Renshaw AA, Cartagena N, Schenkman RH, Derhagopian RP, Gould EW. Atypical Ductal Hyperplasia in Breast Core Needle Biopsies. American Journal of Clinical Pathology. 2001 07;116(1):92-96. https://doi.org/10.1309/61hm-89td0m31-jahh

7. Harvey JM, Sterrett GF, Frost FA. Atypical ductal hyperplasia and atypia of uncertain significance in core biopsies from mammographically detected lesions: correlation with excision diagnosis. Pathology. 2002;34(5):410-416. https:// doi.org/10.1080/0031302021000009315

8. Bonnett M, Wallis T, Rossmann M, Pernick NL, Bouwman D, Carolin KA, Visscher D. Histopathologic Analysis of Atypical Lesions in Image-Guided Core Breast Biopsies. Modern Pathology. 2003 02;16(2):154-160. https://doi. org/10.1097/01.mp.0000052375.72841.e2

9. Jackman RJ, Birdwell RL, Ikeda DM. Atypical Ductal Hyperplasia: Can Some Lesions Be Defined as Probably Benign after Stereotactic 11-gauge Vacuum-assisted Biopsy, Eliminating the Recommendation for Surgical Excision?. Radiology. 2002 08;224(2):548-554. https://doi.org/10.1148/ radiol.2242011528

10. Ely KA, Carter BA, Jensen RA, Simpson JF, Page DL. Core Biopsy of the Breast With Atypical Ductal Hyperplasia. The American Journal of Surgical Pathology. 2001 08;25(8):1017-1021. https://doi.org/10.1097/00000478200108000-00005

11. Sneige N, Lim SC, Whitman GJ, Krishnamurthy S, Sahin AA, Smith TL, Stelling CB. Atypical Ductal Hyperplasia Diagnosis by Directional Vacuum-Assisted Stereotactic Biopsy of Breast Microcalcifications. American Journal of Clinical Pathology. 2003 02;119(2):248-253. https://doi. org/10.1309/0gyv4f2lljav4gfn

12. Clinical guidelines for diseases of the breast. Breast Cancer Research Center. ACECR. Third edition 2018.

13. Chae B, Lee A, Song B, Jung S. Predictive factors for breast cancer in patients diagnosed atypical ductal hyperplasia at core needle biopsy. World Journal of Surgical Oncology. 2009;7(1):77. https://doi.org/10.1186/1477-7819-7-77

14. Lakhani SR, Collins N, Stratton MR, Sloane JP. Atypical ductal hyperplasia of the breast: clonal proliferation with loss of heterozygosity on chromosomes $16 \mathrm{q}$ and $17 \mathrm{p} .$. Journal of Clinical Pathology. 1995 07 01;48(7):611-615. https://doi. org/10.1136/jcp.48.7.611

15. Moon SM, Jung HK, Ko KH, Kim Y, Lee KS. Management of Clinically and Mammographically Occult Benign Papillary Lesions Diagnosed at Ultrasound-Guided 14-Gauge Breast Core Needle Biopsy. Journal of Ultrasound in Medicine. 201609 14;35(11):2325-2332. https://doi.org/10.7863/ ultra.15.11049
16. Samples LS, Rendi MH, Frederick PD, Allison KH, Nelson HD, Morgan TR, Weaver DL, Elmore JG. Surgical implications and variability in the use of the flat epithelial atypia diagnosis on breast biopsy specimens. The Breast. 2017 08;34:34-43. https://doi.org/10.1016/j. breast.2017.04.004

17. Acott A, Mancino A. Flat epithelial atypia on core needle biopsy, must we surgically excise? The American Journal of Surgery. 2016 Dec;212(6):1211-1213. https://doi. org/10.1016/j.amjsurg.2016.09.019

18. Morton MJ, Whaley DH, Brandt KR, Amrami KK. Screening Mammograms: Interpretation with Computeraided Detection-Prospective Evaluation. Radiology. 2006 05;239(2):375-383. https://doi.org/10.1148/ radiol.2392042121

19. Bruening W, Fontanarosa J, Tipton K, Treadwell JR, Launders J, Schoelles K. Systematic review: comparative effectiveness of core-needle and open surgical biopsy to diagnose breast lesions. Ann Intern Med. 2010; 152:23846. https://doi.org/10.7326/0003-4819-152-1-20100105000190PMid:20008742

20. Mooney KL, Bassett LW, Apple SK. Upgrade rates of high-risk breast lesions diagnosed on core needle biopsy: a single-institution experience and literature review. Modern Pathology. 201608 19;29(12):1471-1484. https://doi. org/10.1038/modpathol.2016.127

21. Dyrstad SW, Yan Y, Fowler AM, Colditz GA. Breast cancer risk associated with benign breast disease: systematic review and meta-analysis. Breast Cancer Research and Treatment. 201501 31;149(3):569-575. https://doi.org/10.1007/s10549014-3254-6

22. Lewis MC, Irshad A, Ackerman S, Cluver A, Pavic D, Spruill L, Ralston J, Leddy RJ. Assessing the Relationship of Mammographic Breast Density and Proliferative Breast Disease. The Breast Journal. 201606 04;22(5):541-546. https://doi.org/10.1111/tbj.12620

23. Mesurolle B, Perez JCH, Azzumea F, Lemercier E, Xie X, Aldis A, Omeroglu A, Meterissian S. Atypical Ductal Hyperplasia Diagnosed at Sonographically Guided Core Needle Biopsy: Frequency, Final Surgical Outcome, and Factors Associated With Underestimation. American Journal of Roentgenology. 2014 06;202(6):1389-1394. https://doi. org/10.2214/ajr.13.10864

24. Calhoun BC, Sobel A, White RL, Gromet M, Flippo T, Sarantou T, Livasy CA. Management of flat epithelial atypia on breast core biopsy may be individualized based on correlation with imaging studies. Modern Pathology. 2014 Nov 21;28(5):670-676. https://doi.org/10.1038/ modpathol.2014.159

25. Murray MP, Luedtke C, Liberman L, Nehhozina T, Akram M, Brogi E. Classic lobular carcinoma in situ and atypical lobular hyperplasia at percutaneous breast core biopsy. Cancer. 2012 Nov 06;119(5):1073-1079. https://doi. org/10.1002/cncr. 27841

26. Ueng SH, Mezzetti T, Tavassoli FA. Papillary neoplasms of the breast: a review. Arch Pathol Lab Med. 2009; 133:89307.

27. Shin HJ, Kim HH, Kim SM, Yang HR, Sohn J, Kwon GY, Gong G. Papillary Lesions of the Breast Diagnosed at Percutaneous Sonographically Guided Biopsy: Comparison of Sonographic Features and Biopsy Methods. American Journal of Roentgenology. 2008 03;190(3):630-636. https:// doi.org/10.2214/ajr.07.2664

28. Skandarajah AR, Field L, Yuen Larn Mou A, Buchanan M, Evans J, Hart S, Mann GB. Benign Papilloma on Core Biopsy Requires Surgical Excision. Annals of Surgical 
Oncology. 200805 13;15(8):2272-2277. https://doi. org/10.1245/s10434-008-9962-6

29. Tseng H, Chen Y, Chen S, Wu Y, Kuo S, Chen L, Wu H, Chen D. The management of papillary lesion of the breast by core needle biopsy. European Journal of Surgical Oncology (EJSO). 2009 01;35(1):21-24. https://doi.org/10.1016/j. ejso.2008.06.004

30. Jaffer S, Nagi C, Bleiweiss IJ. Excision is indicated for intraductal papilloma of the breast diagnosed on core needle biopsy. Cancer. 200907 01;115(13):2837-2843. https://doi. org/10.1002/cncr.24321

31. Chang JM, Moon WK, Cho N, Han W, Noh D, Park I, Jung E. Risk of carcinoma after subsequent excision of benign papilloma initially diagnosed with an ultrasound (US)-guided 14-gauge core needle biopsy: a prospective observational study. European Radiology. 2009 Nov 05;20(5):1093-1100. https://doi.org/10.1007/s00330-009-1649-2

32. Wiratkapun C, Keeratitragoon T, Lertsithichai P, Chanplakorn N. Upgrading rate of papillary breast lesions diagnosed by core-needle biopsy. Diagnostic and Interventional Radiology. 201307 25;. https://doi.org/10.5152/dir.2013.017

33. Seely JM, Verma R, Kielar A, Smyth KR, Hack K, Taljaard M, Gravel D, Ellison E. Benign Papillomas of the Breast Diagnosed on Large-Gauge Vacuum Biopsy compared with 14 Gauge Core Needle Biopsy - Do they require surgical excision?. The Breast Journal. 2016 Oct 31;23(2):146-153. https://doi.org/10.1111/tbj.12702

This work is licensed under a Creative Commons AttributionNon Commercial 4.0 International License. 